\title{
Challenges and Countermeasures of Medical Postgraduate Training under the New Situation
}

\author{
Yanqin Sun ${ }^{1, \#, ~ S i y u a n ~ G a n ~}{ }^{1, \#}$, Ruifang Ye ${ }^{2, \#, ~ R u j i a ~} \mathbf{L i}^{1, *}$, Yanmei Yi ${ }^{3, *}$ \\ ${ }^{1}$ Department of Pathology, Guangdong Medical University, Guangdong 523808, China \\ ${ }^{2}$ Dongguan Key Laboratory of Environmental Medicine, School of Public Health, Guangdong Medical University, \\ Guangdong 523808, China \\ ${ }^{3}$ Department of Histoembryology, Guangdong Medical University, Guangdong 524023, China \\ ${ }^{\#}$ These authors contributed equally to this work \\ *Corresponding Authors
}

\begin{abstract}
Graduate education is an important part of medical education. At present, academic graduate students are still the mainstream training mode. This mode focuses on cultivating graduate students' scientific research ability, but often ignores the training of clinical skills required for medical services in future jobs. This paper uses an online questionnaire to investigate the learning status of academic postgraduates in Guangdong Medical University, then finds some problems in the current cultivation of medical academic postgraduates, deeply considers and discusses the existing problems, and puts forward some views on how to cultivate postgraduates with both scientific research literacy and clinical skills. It is expected to have reference value for the reform of academic postgraduate training program.
\end{abstract}

Keywords: Medical education, Postgraduate, Retrospective study.

\section{Introduction}

Under the background of the popularization of higher education, postgraduate medical education has also developed rapidly[1]. With the continuous expansion of postgraduate medical education in China, the quality problems of postgraduate education have become increasingly severe. How to rationally arrange training plans and train qualified doctors with both scientific research and clinical abilities[2].

Medical academic postgraduate education is guided by academic research and focuses on theory and research. Its main objective is to train university teachers and researchers in scientific research institutions in medicine. The types of degrees awarded are mainly academic, and the proportion of professionals is relatively tiny. Therefore, basic science research training is an integral part of the academic master's graduate training plan. However, as medical graduates, many students plan to engage in medical work after graduation; clinical skills training is also vital[3].

Based on the current confusion in the training process of an academic master, this paper carries out a detailed questionnaire survey on partial academic master students and explores the existing problems in the training mode of an academic master. The questionnaire covers two aspects, which are basic scientific research training and evaluation of clinical work skills. The results reported will provide significant evidence for the training system reform of medical academic master students.

\section{Methods}

In this study, we randomly selected 51 medical academic master degree, postgraduate students in Guangdong Medical University from grade 2017, grade 2018, and grade 2019 in the affiliated hospital of Guangdong Medical University as the research subjects (The detailed information is listed in table 1). The academic master's degree postgraduate students will obtain an academic medical master's certificate. They can also obtain a licensed doctor's certificate through a Chinese medical licensing examination, but that is unnecessary. In order to engage in clinical medical work in the future, three years of standardized training for resident physicians is required first. In this study, the Wechat program "Questionnaire Star" was used for investigation and analysis.

Table 1: Affiliations of academic postgraduate students.

\begin{tabular}{|l|c|}
\hline Survey respondents & Number \\
\hline Sum of graduate students surveyed & 51 \\
\hline Sex & 16 \\
\hline Male & 35 \\
\hline Female & 51 \\
\hline Type & 0 \\
\hline Academic type & \\
\hline Professional type & 2 \\
\hline Grade & 42 \\
\hline $1^{\text {st }}$ year master & 7 \\
\hline $2^{\text {nd }}$ year master & \\
\hline $3^{\text {rd }}$ year master & \\
\hline
\end{tabular}

\section{Results/Analysis}

As shown in Figure 1, the scientific research subjects of academic postgraduates are mainly primary study type (69\%), followed by clinical research type (21\%) and the applied research type (8\%). The sources of these projects are different; most of them are their tutors' fund projects $(88 \%)$, followed by the collaborative projects of the tutors' group (6\%) and self-selected projects from work (6\%). In terms of time input, most of the students spent more than 24 months on the subject research $(90 \%)$, while some of them still spent less than six months $(4 \%)$ or between 6 and 24 months $(6 \%)$. Regarding the output of scientific research achievements, $34 \%$ of the graduate students have published 1 3 papers in Chinese core journals, and $16 \%$ of the graduate students have published papers in Scientific Citation Index journals. However, it should not be ignored that $45 \%$ of the graduate students have not yet published their papers. Regarding paper types, $47 \%$ of the students have published reviews, and only $19 \%$ have published academic works. 

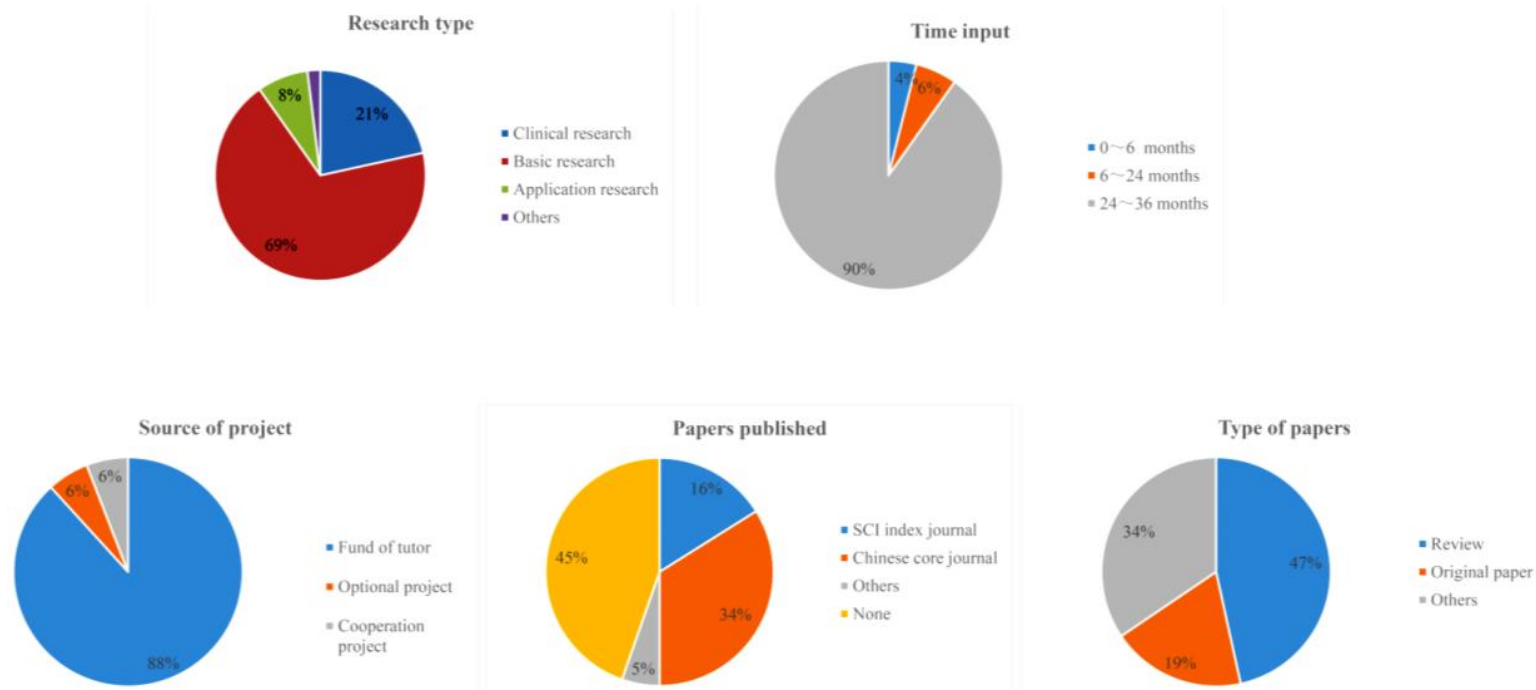

Figure 1: Research investment and achievements of academic postgraduates.

As shown in Figure 2, the survey shows that postgraduates receive less clinical skills training, $82 \%$ have never received clinical professional training, while only $16 \%$ have received more than 6 hours' clinical professional skills training every day (Figure 2). A Chinese medical licensing examination assesses clinical professional knowledge and skills. Our investigation showed that $49 \%$ of the students had never enrolled in the exam, $12 \%$ failed, and only $19 \%$ of the graduate students successfully passed the examination (Figure 2).
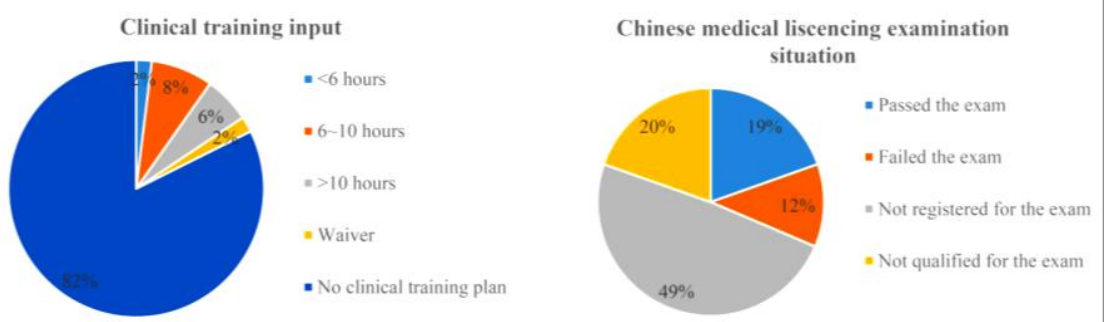

Figure 2: Professional skills situation of academic postgraduates

As shown in Figure 3, in the aspect of scientific research training, $67 \%$ of the postgraduates reflect that their disciplines adopt the training mode of a tutor group and carry out subject reporting and literature reading in a planned way. Experience communication within the tutor group can significantly improve their research level. In addition, $63 \%$ of the graduate students thought that the most reasonable and effective way was carrying out research based on independent study and cooperation with students inside the discipline. Our April
2020 showed that $74 \%$ of the graduate students in July 2020 have not yet started writing their dissertations, 9\% had completed partly, and only $17 \%$ had finished their dissertations. On the other hand, the career planning of graduates after graduation is diversified, $24 \%$ intended to work in universities or scientific research institutions, $18 \%$ intended to work in government departments, and 13\% intended to work in enterprises, $16 \%$ chose to study in China and $5 \%$ planned to study abroad.
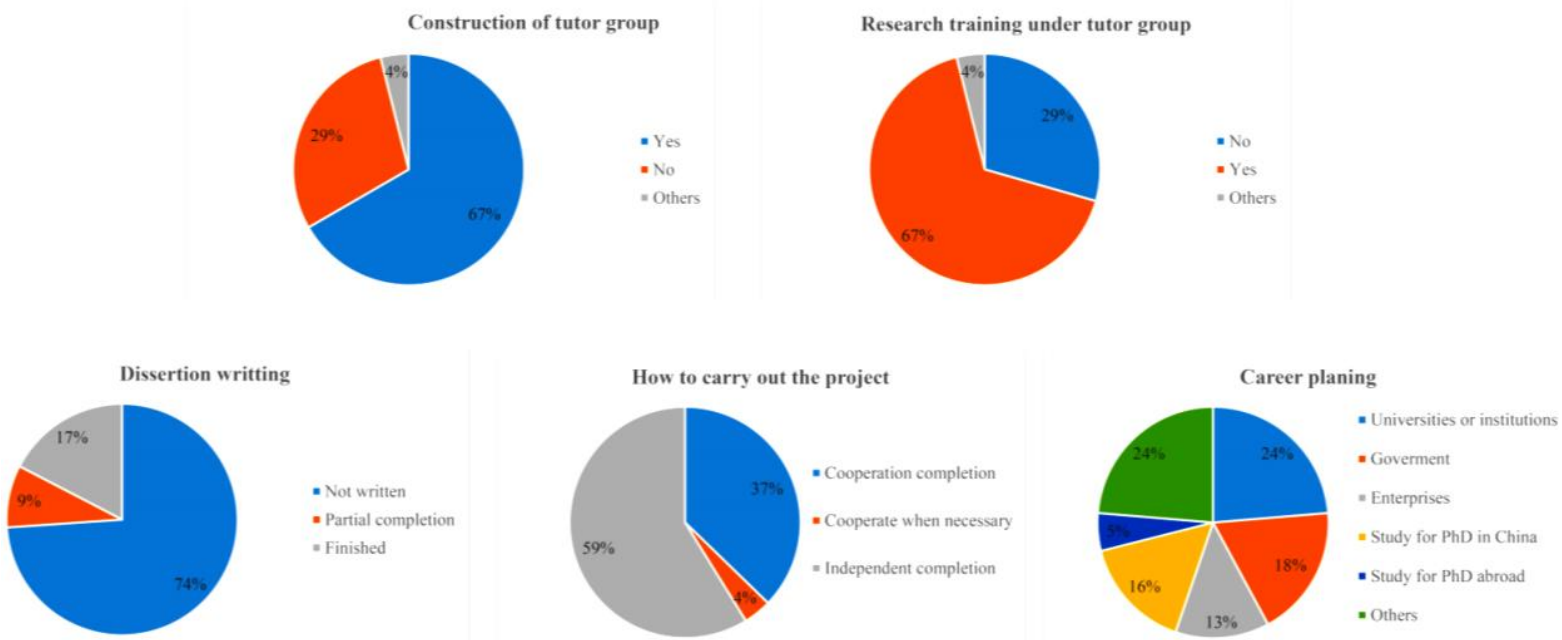

Figure 3: Research promotion strategy and career planning of graduates in 2020. 
As shown in Figure 4, 60\% of graduate students keep communicating with their tutors at any time, and $33 \%$ of graduate students communicate with their tutors once a week. In terms of communication methods, face-to-face communication is more frequent, including regular face-to-face $(41 \%)$ and irregular face-to-face communication $(35 \%) ; 24 \%$ of students use non-face-to-face communication with their tutors. In terms of contact methods, most of them Communication methods
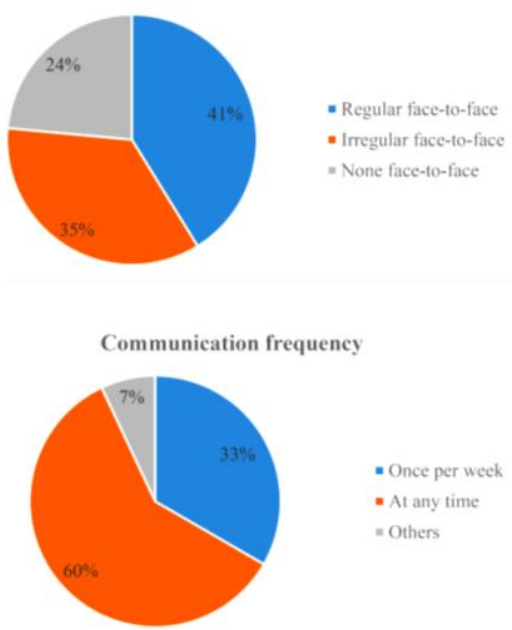

Figure 4: Communication with tutors and participation in academic conferences.

\section{Discussion}

It has to be admitted that in recent years, a considerable part of academic tutors in most medical universities insist that the scientific research results are the touchstone for postgraduates' study, but also a knock-in brick for job-hunting after graduation. They believe that high-intensity basic scientific research training is the top way to train academic master students. In terms of the time arrangement and normative degree of clinical skills training, the requirements are deficient, which leads to the clinical professional level of academic master students being even lower than that of bachelor undergraduates after graduation[4]. On the contrary, the other academic mentors have serious clinical business and are too busy to supervise their graduate students. Usually, due to the shortage of doctors in the hospital, academic master students are trained as clinical professional graduate students. Combining the relationship between clinical practice ability training and scientific research training by reforming the postgraduate training mode and improving the quality of postgraduate training has become a broad concern issue.

Based on the results of this survey, it is found that most academic graduate students are almost entirely engaged in scientific research training of partial basic research. However, the output of scientific research is not ideal. Only about half of the graduate students have published papers $(55 \%)$, and the type of most papers is the review (47\%). On the other hand, most fresh graduates in 2020 have not completed the subject and published relevant papers. We speculate that may be due to some disciplines' lack of standardized scientific research training and less communication with the tutors. It is well known that a considerable proportion of the tutor's laissez-faire training leads to a scattered postgraduate. Some students realized it was challenging to meet the graduation standards even until graduation[5]. use a phone, message, WeChat, $\mathrm{QQ}$, etc. The tutors' concern for graduate students involves studying life, thesis writing, subject research, employment guidance, etc. Regarding foreign exchange and learning, $57 \%$ of the students have attended 1 3 academic conferences in this field during their postgraduate period, $18 \%$ have attended $4 \sim 6$ academic conferences, and $19 \%$ have even attended more than six academic conferences.
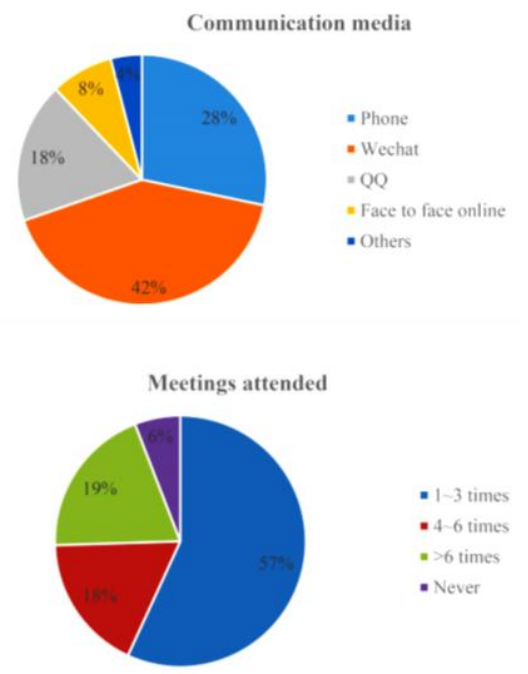

Based on the above, we propose the following considerations. First, how to complete the basic clinical skills training arrangement under the premise of ensuring the academic master to carry out high-intensity basic scientific research training? Secondly, how to improve the next training plan when the training discipline cannot give postgraduates the necessary training, especially their failure in the mid-term examination? In addition, a considerable number of graduate students will engage in clinical work after graduation. Whether the Chinese medical licensing examination should be regarded as one of the graduation requirements? With the above concerns, we will carry out a further study on the reform of the training mode of academic graduate students, hoping to provide better talents for social, medical services.

\section{Conclusion}

At present, our university's medical academic postgraduate training mode focuses on basic scientific research training, which is insufficient in their clinical professional knowledge and skills training. Although postgraduates have invested too much energy in basic science research, the output of scientific research results has not been satisfactory. Therefore, next, we will search for a better postgraduate training mode through in-depth study.

\section{Acknowledgement}

This work is supported by projects: Guangdong Postgraduate Education Innovation Program (NO.2019JGXM56); Guangdong Education Science "13th-five year plan" Research Project of 2020 (NO.2020GXJK412); Research topic of higher education in 2021 of the "14th five year plan" of Guangdong Higher Education Society (NO.21GYB158); Undergraduate teaching quality and teaching reform project 
of Guangdong Medical University (NO.1JG21096); Special project on Teaching Research of curriculum ideological and Political Education of Guangdong Medical University (NO.2SZ21020); Guangdong Higher Education Reform Program (NO.2018270); Guangdong Province Educational Science Planning Project of 2021 (Higher Education Special Project) (NO. 2021GXJK468); Guangdong province Graduate Education Innovation Program (2022XSLT032).

\section{References}

[1] Tolsgaard, M. G., Kulasegaram, K. M. and Ringsted, C. (2017) "Practical trials in medical education: linking theory, practice and decision making", Med Educ, 51(1), Fpp. 22-30.

[2] Laury P. J. W. M. de Jonge, Ilse Mesters, Marjan J. B. Govaerts, Angelique A. Timmerman, et al. (2020) "Supervisors intention to observe clinical task performance: an exploratory study using the theory of planned behaviour during postgraduate medical training”, BMC Med Educ, 20(1), pp. 134-143.

[3] Brand PLP, Rosingh HJ, Meijssen MAC, Nijholt IM, et al. (2019) 'Reliability of residents' assessments of their postgraduate medical education learning environment: an observational study", BMC Med Educ, 19(1), pp. 450-456.

[4] Bugaj TJ, Valentini J, Miksch A and Schwill S. (2019) "Work strain and burnout risk in postgraduate trainees in general practice: an overview". Postgrad Med, 132(1). pp. 1-30.

[5] Woldekidan NA, Mohammed AS and Belachew EA. (2020) "Pharmacy Students Motivation, Preparation and Factors Affecting Pursuing Postgraduate Education in Ethiopian University”, Adv Med Educ Pract, 2020(11), pp. 429-436. 